\title{
Production of PVC granules can boost plastic and chemical industries in Bangladesh
}

\section{Editorial}

Thermoplastic is an engineered material with the characteristics of low-density, toughness, rigidity, flexibility, low cost, ease of processing and reshaping, and non-rusting, etc. It is nowadays globally used to manufacture numerous products for various applications.

The plastic industry is relatively new in Bangladesh. There are now around 3000 plastic factories in the country; almost all belong to the small and medium enterprises. Covering the domestic market of a size of around 1.15 billion USD, Bangladesh's plastic products are being exported to many foreign countries as direct plastic products made an earnings of around US \$69 million in FY 2010-11, with accessories (deemed export) making an earning of around US\$ 286 million in the same fiscal. The growth of direct export per year in the last decade was 20.2 per cent, while that of deemed export was also remarkably high. The plastic industry has already emerged in Bangladesh as a vibrant sector with a significantly high growth potential. Nevertheless, there has been no production of polymer granules, the raw materials for plastic processing industries, in Bangladesh yet. The entire sector is consequently depending on the imported polymer granules.

In the fiscal year of 2010-11, 696540 MT granules of a value of $\$ 918$ million were imported in total. A variety of polymer granules such as poly ethylene (HDPE and LDPE), poly vinyl chloride (PVC), poly propylene (PP), poly ethylene terepthalate (PET), poly styrene (PS) and others are imported to Bangladesh.

In general, producing polymer granules domestically would save foreign currency partly, create new employment opportunities and secure the growth and stability in plastic sector. However, producing PVC granules particularly is of great interest for Bangladesh now, since it can also be a direct means for the expansion of chlor-alkali (i.e., basic chemical) industries in Bangladesh.

Caustic soda $(\mathrm{NaOH})$ is a basic chemical used in soap, glass, drugs, paper \& pulp, textile, leather, sugar, WTP and ETP etc industries in Bangladesh. The demand of caustic soda has been increasing gradually, which for the fiscal 2011-12 is predicted to be 1, 53,608 MT. Under this circumstance, there are only few chlor-alkali industries in Bangladesh to produce this soda. The total production capacity is now 290 MT per day and 95,700 MT per year. The existing production capacity lagged behind the FY 2011-12's demand by 38 per cent. Moreover, the total yearly production is now substantially lower than production capacity even though the demand is remarkably high. Hence, the balance demand is met through the import from foreign markets. The growth per year in the import of last eight years was around 5.0 per cent.

The reason behind the lower production of caustic soda is the lower demand of chlorine $\left(\mathrm{Cl}_{2}\right)$, which is a bi-product of the chloralkali plants in Bangladesh currently. The plants are operating at lower production rate mainly to have less amount of chlorine since chlorine has low demand in Bangladesh. If it is possible to create a proper demand for chlorine produced from the chlor-alkali plants, it is certainly possible for the plants to operate at their full production capacity. Even it is quite possible to build more chlor-alkali plants
Volume 2 Issue 5 - 2017

\author{
Md lqbal Hossain \\ Department of Chemical Engineering, Bangladesh University of \\ Engineering and Technology, Bangladesh
}

Correspondence: Md lqbal Hossain, Department of Chemical Engineering, Bangladesh University of Engineering and Technology, Bangladesh, Email iqbalhossain@che.buet.ac.bd

Received: June 04, 2017 | Published: June 14, 2017

resulting in no import of caustic soda from foreign countries. PVC granule-producing plants (i.e., VCM section) consume chlorine as a raw material.

A typical PVC granules plant requires chlorine at 400 MT per day, while our total current production capacity is $250 \mathrm{MT}$ per day. Hence, developing a PVC granule-producing plant can create a scope for the consumption of chlorine produced from local chlor-alkali plants. It can create a very good scope for the expansion of chlor-alkali industries in Bangladesh.

$\mathrm{PVC}$ is produced by the polymerization reaction of vinyl chloride monomer $(\mathrm{CH} 2 \mathrm{CHCl}, \mathrm{VCM})$. The principal feedstock needed to produce PVC is VCM. Generally, there are two routes to synthesize VCM, which are acetylene route and ethylene route. However, the ethylene route is commonly adopted worldwide nowadays, since ethylene is less costly than acetylene. In the context of Bangladesh, the ethylene route is also preferred if the ethylene can be made available conveniently.

There are two special reasons for adopting ethylene route:

(i) Ethylene route utilise chlorine which can directly be supplied by the local chlor-alkali industries.

(ii) Ethylene needed to produce VCM is also needed to domestically produce the PE polymer granules, which are also consumed in Bangladesh at a very large amount. A common effort can be made to procure the ethylene for both (PVC and PE) applications.

There are three options for the procurement of ethylene. Firstly, it can directly be imported from foreign countries. Secondly, liquefied petroleum gas (LPG) can be imported and the ethylene can then be produced from the imported LPG through the pyrolysis process. A pyrolysis plant is also required to be developed in the second option. A large number of imported condensate fractionation plants are in Bangladesh. Naphtha or gasoline obtainable from the condensate fractionation plants can give ethylene through a pyrolysis process. A pyrolysis plant is also needed in the third option. This option seems to be more secure and economical for procuring ethylene to produce VCM through ethylene route. Hence, a collective effort must have to be put in by the plastic industry (especially PVC and PE-based industry), chlor-alkali industry and the government to develop the required facilities. 


\section{Acknowledgements}

None.

\section{Conflict of interest}

The author declares no conflict of interest. 